\title{
A monoclonal macroglobulin with antinuclear activity
}

\author{
L. INTRATOR, C. ANDRE, C. CHENAL, AND C. SULTAN \\ From the Service Central d'Hématologie-Immunologie, Hopital Henri Mondor et Département \\ d'Hématologie Biologique de la Faculté de Médecine de Créteil, Créteil 94010, France
}

SUMMARY Serum containing a monoclonal IgM protein from a patient with Waldenströms' macroglobulinaemia gave intense immunofluorescent staining of kidney nuclei. The Fab $\mu$ fragments of this immunoglobulin were obtained. The IgM and Fab fragments reacted in vitro with kidney nuclei using unfixed cryostat sections of rat or mouse kidney. After treatment of the patient with chemotherapy, the monoclonal IgM disappeared, and no more antinuclear activity could be detected in the serum. The results strongly suggest that this IgM protein had antinuclear activity.

Numerous monoclonal serum immunoglobulins with antibody activity have been reported in recent years (Potter, 1971; Seligmann and Brouet, 1973). Such activities are usually found in lymphoproliferative malignancies, mainly Waldenström's macroglobulinaemia and multiple myeloma, but they may also be detected in benign monoclonal gammopathies and liver diseases (Roux et al., 1974). Several have been considered as monoclonal autoantibodies.

This report documents the first monoclonal macroglobulin of kappa type with antinuclear activity to kidney cells and demonstrates the specificity of the reactions of $\operatorname{IgM}$ and Fab $\mu$ with kidney nuclei.

\section{Case report}

A man aged 43 was first seen in September 1975. He complained of recent weakness and bruising of the arms. Physical examination was normal. The blood picture showed pancytopenia; WBC $1.6 \times 10^{9} / 1$ (with $65 \%$ lymphoid cells, $30 \%$ neutrophils, and $5 \%$ monocytes), Hb $3.7 \mathrm{~g} / \mathrm{dl}$, RBC $1.1 \times 10^{12} / 1$ (with anisocytosis, poikylocytosis, macrocytosis, and schizocytes), haematocrit $11.9 \%$, reticulocytes $28 \times$ $10^{9} / 1$ on absolute count, platelets $13 \times 10^{9} / 1$. Erythrocyte sedimentation was $175 \mathrm{~mm}$ in the first hour. The bone marrow obtained by aspiration was hypocellular with $86 \%$ lymphocytes. Megakaryocytes were not observed. Bone marrow biopsy showed extensive myelofibrosis with lymphocytic infiltration.

Received for publication 12 October 1978
The total serum protein was $73 \mathrm{~g} / 1$ with $17 \mathrm{~g} / 1$ peak in the $\gamma$ globulin fraction. Immunoelectrophoresis showed a monoclonal IgM of the kappa type. The polyclonal IgG and IgA globulin levels were normal without Bence Jones proteinuria. Serum antinuclear factor to rat kidney nuclei was found with a titre of $1 / 100000$, giving a coarsely granular pattern; this procedure is routinely performed in our laboratory, and details are described below. No anti double strand (ds) and single strand (ss) DNA antibody activity and no anti ENA (extractable nuclear antigen) were detected. All other laboratory studies were normal. Lymphography was normal. The above clinical and serological manifestations did not respond to six weeks' treatment with prednisone ( $1 \mathrm{mg} / \mathrm{kg})$; the patient therefore received combination chemotherapy (COPP). By April 1976 the monoclonal IgM peak was barely evident and simultaneously the antinuclear factors were detected only with a titre of $1 / 10$. In November 1976 the monoclonal IgM was undetectable by immunoelectrophoresis. There was no antinuclear activity although polyclonal IgM was present at a concentration of $0.6 \mathrm{~g} / \mathrm{l}$.

\section{Material and methods}

\section{SEPARATION OF THE MONOCLONAL IgM}

The serum was kept frozen at $-20^{\circ}$. The $\beta$ lipoproteins were precipitated by dextran sulphate and the euglobulins by boric acid. Fractionation of the serum was carried out using gel filtration on Sephadex $\mathrm{G} 200$ in $0.2 \mathrm{M}$ tris $\mathrm{HCl}, 1 \mathrm{M} \mathrm{NaCl}$ buffer $\mathrm{pH}$ 8. The ascending half of the exclusion peak con- 
tained only the IgM globulin. The descending peak and a second peak containing IgG and IgA globulins were kept.

\section{FRAGMENTATION OF THE MONOCLONAL IgM} BY PAPAIN

Papain digestion of the monoclonal IgM was performed using the technique described by Mihaesco and Seligmann (1968). The 24-hour digests were submitted to gel filtration on Sephadex G200 columns. The elution peaks corresponding to $\mathrm{Fc} \mu$ and Fab $\mu$ were concentrated and tested by immunoelectrophoresis and Ouchterlony techniques against rabbit antisera (CDTS Rouen and Sebia).

\section{PREPARATION OF SUBUNITS}

Purified IgM was reduced with 0.1 M 2 mercaptoethanol in $0.1 \mathrm{M}$ tris $\mathrm{HCl}, 1 \mathrm{M} \mathrm{NaCl}$ buffer $\mathrm{pH} 8$ and alkylated with a $10 \%$ molar excess of iodoacetamide.

STUDY OF THE ANTINUCLEAR ACTIVITY OF THE MONOCLONAL IgM AND ITS FRAGMENTS The antinuclear activity of the whole serum, of the purified IgM preparation, and of the fragments was measured by indirect immunofluorescence using unfixed cryostat sections of rat or mouse kidney and fluorescein conjugated rabbit antisera specific to human IgG, IgA, IgM, and kappa and lambda chains (Hyland and Sebia). Slides were examined on a fluorescence epiconcienser Zeiss IV FL.

\section{ENZYMATIC TREATMENT OF TISSUE SLIDES}

This was carried out using deoxyribonuclease (DNase) and ribonuclease (RNase) obtained from the Worthington Biochemical Corporation at a concentration of $4 \mathrm{mg} / 100 \mathrm{ml}$ in saline solution with a pH of 7 containing $0.4 \mathrm{mM}$ magnesium chloride at $37^{\circ} \mathrm{C}$ for 60 minutes. Fixed or unfixed sections were immersed in these solutions and then washed and stained for immunofluorescent analysis (Tan and Kunkel, 1966).

Digestion with trypsin $(0.1 \mathrm{mg} / \mathrm{ml}$ and $0.01 \mathrm{mg} / \mathrm{ml})$ on tissue section was performed for 30 minutes at room temperature (Bianchi et al., 1974).

\section{Results}

\section{THE WHOLE SERUM}

Figure 1 shows the cellulose acetate electrophoretic pattern of the patient's serum. The concentration of the abnormal monoclonal peak was $17 \mathrm{~g} / 1$. Immunoelectrophoretic analysis of the patient's serum and of the isolated IgM established that the abnormal constituent was an IgM with a kappa chain (Figs 2 and 3).

Antinuclear activity to rat kidney cells was

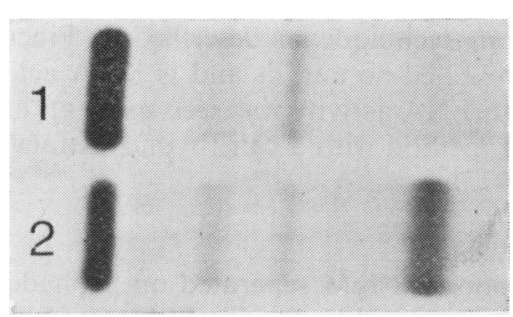

Fig. 1 Cellulose acetate electrophoresis of the patient's serum: (1) control; (2) patient's serum. Anode to the left.

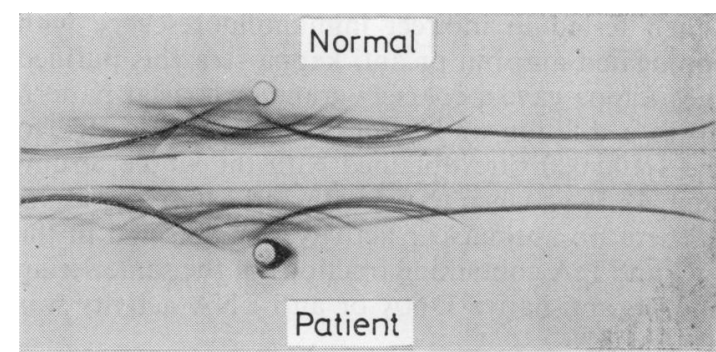

Fig. 2 Immunoelectrophoretic analysis of the patient's serum against anti human normal serum. Dense agglomerates of protein that fail to diffuse are seen around the patient sample well (bottom well). Anode to the left.

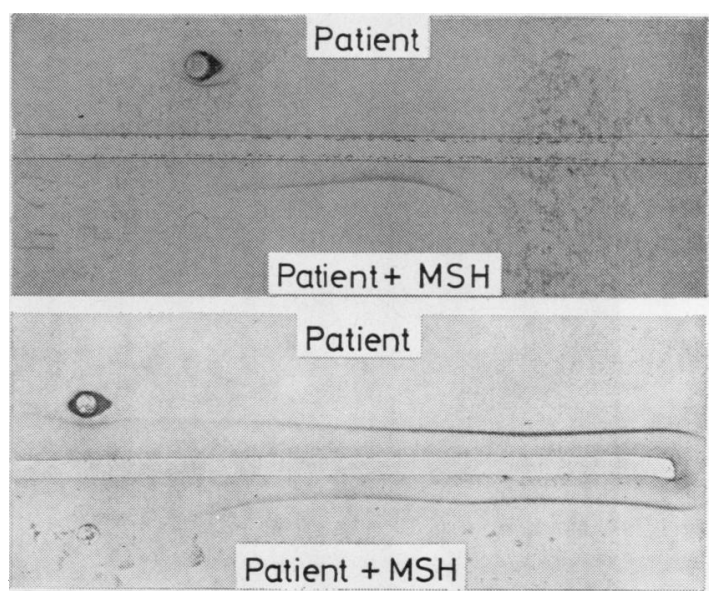

Fig. 3 The dense agglomerates of protein (top wells) are depolymerised with 2 mercaptoethanol (bottom wells) and revealed by anti $\mathrm{mu}$ (a) and anti kappa (b) antisera. Anode to the left. $M S H=$ mercaptoethanol.

observed to a titre of $1 / 100000$ and a coarsely granular nuclear pattern with anti whole gamma globulin, anti mu, and anti kappa antisera. With anti alpha, gamma, and lambda antisera no antinuclear activity was demonstrated. 
The Farr technique, as described by Pincus et al. (1969), revealed no anti ds and ss DNA activity.

No anti ENA activity was seen using an immunodiffusion method with a calf thymus extract (Peltier et al., 1977).

\section{PURIFIED IgM}

The monoclonal IgM separated on Sephadex G200 columns was tested by the Ouchterlony technique at a concentration of $10 \mathrm{mg} / \mathrm{ml}$; only one line of precipitation was observed with anti whole human serum or with anti mu and kappa antisera and none with anti alpha, gamma, and lambda chain antisera. When tested in indirect immunofluorescence with conjugated anti mu or anti kappa sera this purified IgM kappa gave a coarsely granular nuclear pattern up to a dilution of $1 \gamma / \mathrm{ml}$ (which corresponded to the $1 / 100000$ titre obtained with the whole serum) (Fig. 4). Even when tested with anti gamma or alpha antisera no antinuclear activity was detected in the IgG and IgA containing fractions of the same serum and no anti-native DNA or anti ENA activity was observed.
SUBUNITS

After depolymerisation of purified IgM by 2 mercaptoethanol the antinuclear activity was markedly decreased.

\section{FRAGMENTS}

The purity of the Fab and Fc fragments at a concentration of $10 \mathrm{mg} / \mathrm{ml}$ was tested by the Ouchterlony technique and by immunoelectrophoresis with anti whole human serum, anti mu, anti kappa, and anti Fab antisera; peak I containing the Fc fragment did not react with anti Fab but was revealed by anti mu antiserum. Peak II containing the Fab fragment was revealed by anti Fab and anti kappa, and not by anti mu antiserum (Fig. 5).

When tested by indirect immunofluorescence, the Fab fragment gave a positive staining of kidney nuclei; this was revealed only by anti kappa antiserum. The Fc fragments gave negative results (Table).

TREATMENT BY DNase, RNase, AND TRYPSIN The immunofluorescent pattern of kidney cryostat

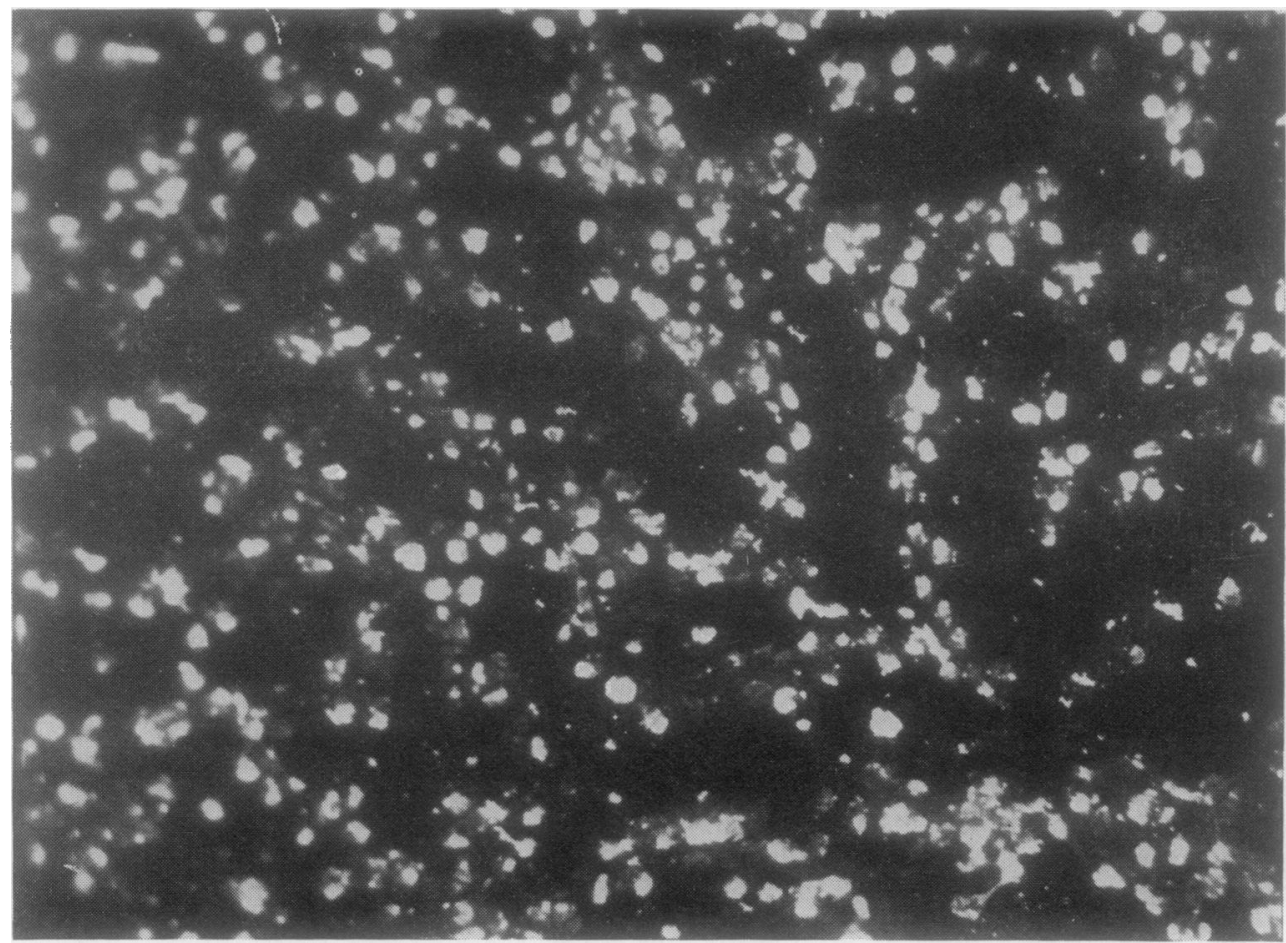

Fig. 4 Immunofluorescent staining of rat kidney section by monoclonal IgM showing strong binding to the nuclei $(\times 160)$. 


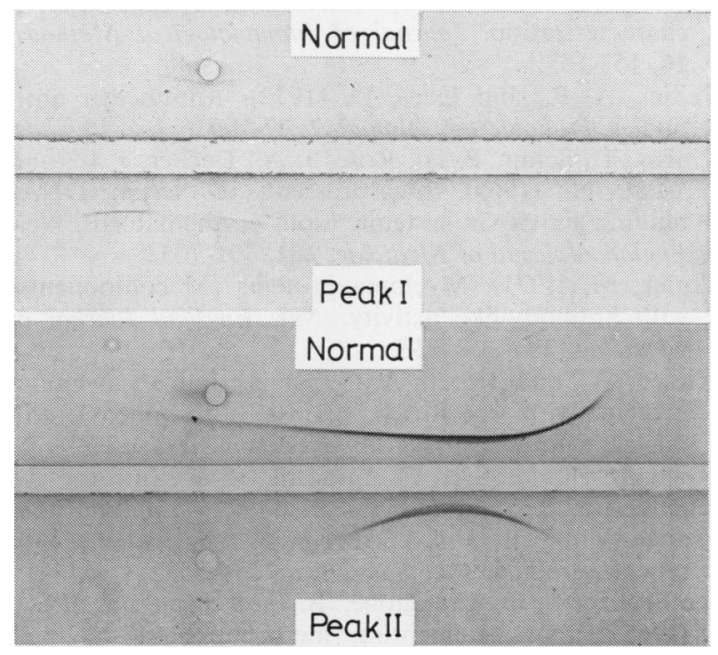

Fig. 5 Immunoelectrophoresis of normal serum (top wells) and IgM papain fragments (bottom wells):

(a) reaction of first elution peak (Fc fragment) with anti mu antiserum; (b) reaction of second elution peak (Fab fragment) with anti Fab antiserum. Anode to the left.

Table Results of immunofluorescence studies applied to rat kidney nuclei

\begin{tabular}{lllll}
\hline $\begin{array}{l}\text { Whole serum } \\
\text { dilution }\end{array}$ & $\begin{array}{l}\text { Purified } \\
\text { monoclonal } \\
\text { IgM }\end{array}$ & $\begin{array}{l}\text { Fractions } \\
\text { containing } \\
I g G \text { and } I g A \text { Aragment }\end{array}$ & $\begin{array}{l}\text { Fab } \mu \\
\text { francentration concentration } \\
12 \mathrm{mg} / \mathrm{ml}\end{array}$ & $\begin{array}{l}\text { Fc } \mu \\
\text { fragment }\end{array}$ \\
\hline $\begin{array}{l}\text { Positive at } \\
\text { a dilution } \\
\text { of } 1 / 100000\end{array}$ & $\begin{array}{l}\text { Positive at } \\
\text { a concentra- } \\
\text { tion of } 1 \mathrm{r} / \mathrm{ml}\end{array}$ & Negative & $\begin{array}{l}\text { Positive at } \\
\text { a dilution } \\
\text { of } 1 / 100\end{array}$ & Negative \\
\hline
\end{tabular}

sections obtained with whole serum and purified IgM was unaffected after treatment by RNase but was completely eliminated or markedly reduced after treatment by DNase. After trypsin treatment, no nuclcar fluorescence was evident but the tissue section was slightly damaged.

\section{Discussion}

This report describes the observation of a monoclonal IgM of $17 \mathrm{~g} / \mathrm{l}$ with antinuclear activity evident in the whole serum with a titre of $1 / 100000$ in a patient with marrow lymphocytosis. This very high titre suggested a possible antinuclear activity of the monoclonal component, and although the exact specificity of this antinuclear activity has not been established, several observations are in favour of this hypothesis:

(a) The negative results of antinuclear tests using anti gamma, alpha, and lambda antisera (or IgG and IgA containing fractions) contrast with the high titres observed with anti mu and anti kappa antisera in the whole serum and the purified macroglobulin.

(b) The positive results with Fab fragments and not with the $\mathrm{Fc}$ fragment.

(c) The parallel disappearance of both the monoclonal IgM and the antinuclear activity (although normal levels of IgG, IgA, and polyclonal IgM were present in the serum).

(d) The abolition of immunofluorescent staining, after treatment by DNase and trypsin, suggests a specificity against some deoxyribonucleoprotein. It should be noted that no antibody activity against ds and ss DNA was found with the Farr technique. These results suggest that both the protein and DNA moiety of nucleoprotein are necessary for the reaction. The antigenic site may be located at the junction of both moieties or may reside on one alone. The union of the two moieties may alter the tertiary structure of one or both components and thereby create or reveal other antigenic sites (Peltier and Estes, 1972).

In previous reports, monoclonal macroglobulin has been shown to possess antibody activity directed against red blood antigens (Christenson et al., 1957; Macris et al., 1970; Rochant et al., 1972) and microbial antigens (Warner et al., 1971; Hauptman and Tomasi, 1973; Stone and Metzger, 1969). It is striking that many monoclonal components are autoantibodies (anti erythrocyte antigens, anti IgG and other plasma proteins, anti gastric parietal cells (Micouin et al., 1977)), and it is therefore possible that cells producing autoantibodies are more likely to undergo neoplastic transformation. Certain monoclonal components are recognised as potentially important in producing overt clinical manifestations. This monoclonal IgM globulin appears to be the first to have an antinuclear activity, although low molecular weight IgM has been described with antinuclear activity (Rothfield et al., 1965; Harisdangkul et al., 1975), and an IgG myeloma protein has been reported to react with single stranded DNA and to a much lesser extent with native DNA (Riesen and Morell, 1972).

Whether this monoclonal IgM is an autoantibody against some deoxyribonucleoprotein is at present not clear. Antinuclear activity has not been associated with recognisable clinical abnormalities, as seen in systemic lupus erythematosus and other connective tissue diseases, and the possibility exists that it is directed against an exogenous source of antigen.

Anti ENA activity was kindly performed by Professeur Peltier, INSERM U 18, Hôpital Lariboisière, Paris. 
We thank Docteur A. Cannat, Institut de Biologie, Montpellier, and Docteur F. Danon, Laboratoire d'Immunochimie, Hôpital Saint Louis, Paris, for advice.

\section{References}

Bianchi, F. B., Rizzetto, M., Penfold, P., Swana, G. T., and Doniach, D. (1974). Ultrastructural localization and characterization of a ribosomal antibody detected by immunofluorescence in systemic lupus erythematosus. Clinical and Experimental Immunology, 17, 629-636.

Christenson, W. N., Dacie, J. V., Croucher, B. E. E., and Charlwood, P. A. (1957). Electrophoretic studies on sera containing high-titre cold haemagglutinins: identification of the antibody as the cause of an abnormal $\gamma_{1}$ peak. British Journal of Haematology, 3, 262-275.

Harisdangkul, V., McDougal, J. S., Knapp, M., and Christian, C. L. (1975). Naturally occurring low molecular weight IgM in patients with rheumatoid arthritis, systemic lupus erythematosus and macroglobulinemia. Journal of Immunology, 115, 216-222.

Hauptman, S., and Tomasi, T. B., Jr. (1973). A monoclonal IgM protein with antibody-like activity for human albumin. Journal of Clinical Investigation, 53, 932-940.

Macris, N. T., Capra, J. D., Frankel, G. J., Ioachim, H. L., Satz, H., and Bruno, M. S. (1970). A lambda light chain cold agglutinin-cryomacroglobulin occurring in Waldenström's macroglobulinemia. American Journal of Medicine, 48, 524-529.

Micouin, C., Rivat, C., Bensa, J. C., Stoebner, P., Favre, M., and Hudry, E. (1977). An human immunoglobulin in a myeloma protein with antigastric parietal cell auto-antigen activity. Clinical and Experimental Immunology, 27, 78-84.

Mihaesco, C., and Seligmann, M. (1968). Papain digestion fragments of human IgM globulins. Journal of Experimental Medicine, 127, 431-453.

Peltier, A. P., Aussel, C., Haim, T., and Cyna, L. (1977). Ribonucleoprotein (RNP) soluble nuclear antigen: demonstration of its reaction with serum antibodies by counter-immunoelectrophoresis and further partial characterization. Journal of Immunological Methods, 16, 153-163.

Peltier, A. P., and Estes, D. (1972). Antinuclear antibodies. Pathobiology Annual, 2, 77-109.

Pincus, T., Schur, P. H., Rose, J. A., Decker, J. L., and Talal, N. (1969). Measurement of serum DNAbinding activity in systemic lupus erythematosus. New England Journal of Medicine, 281, 701-705.

Potter, M. (1971). Myeloma proteins (M components) with antibody-like activity. New England Journal of Medicine, 284, 831-838.

Riesen, W., and Morell, A. (1972). An human myeloma protein with specificity against dinitrophenyl and nucleic acid derivatives. Immunochemistry, 9, 979-985.

Rochant, H., Tonthat, H., Etievant, M. F., Intrator, L., Sylvestre, R., and Dreyfus, B. (1972). Lambda cold agglutinin with anti- $A_{1}$ specificity in a patient with reticulosarcoma. Vox Sanguinis, 22, 45-53.

Rothfield, N. F., Frangione, B., and Franklin, E. C. (1965). Slow sedimenting mercaptoethanol-resistant antinuclear factors related antigenically to $\mathrm{M}$ immunoglobulins in patients with systemic lupus erythematosus. Journal of Clinical Investigation, 44, 62-72.

Roux, M. E. B., Florin-Christensen, A., Arana, R. M., and Doniach, D. (1974). Paraproteins with antibody activity in acute viral hepatitis and chronic autoimmune liver diseases. Gut, 15, 396-400.

Seligmann, M., and Brouet, J. C. (1973). Antibody activity of human myeloma globulins. Seminars in Hematology, 10, 163-177.

Stone, M. J., and Metzger, H. (1969). The specificity of a monoclonal macroglobulin $(\gamma \mathrm{M})$ antibody: reactivity with primate $\gamma \mathrm{G}$ immunoglobulins. Journal of Immuno$\log y, 102,222-228$.

Tan, E. M., and Kunkel, H. G. (1966). An immunofluorescent study of the skin lesions in systemic lupus erythematosus. Arthritis and Rheumatism, 9, 37-46.

Warner, N. L., MacKenzie, M. R., and Fudenberg, H. H. (1971). Anti-antibody activity of a monoclonal macroglobulin. Proceedings of the National Academy of Sciences (Washington), 68, 2846-2851.

Requests for reprints to: L. Intrator, Service Central 윽 d'Hématologie-Immunologie, Hopital Henri Mondor, 94010 Créteil, France. 